\title{
ENTREVISTA A MANUEL ATIENZA ${ }^{1}$
}

\author{
Interview to Manuel Atienza
}

Juan Jesús GARZA ONOFRE2

Resumen: Manuel Atienza (Oviedo, 1951) es catedrático de Filosofía del Derecho en la Universidad de Alicante. Director de la revista DOXA - Cuadernos de Filosofía del Derecho y del máster de argumentación jurídica. Ex vicepresidente de la Asociación mundial de Filosofía Jurídica y Social. Ha sido profesor visitante en la Harvard Law School y en la Cornell University. Doctor Honoris Causa por diversas Universidades Latinoamericanas. Autor de numerosos artículos y unos 20 libros, entre ellos: Las Razones del Derecho (1991), Tras la justicia (1993), Las piezas del Derecho (con Juan Ruiz Manero, 1996; (versión en inglés: : A Theory of Legal Sentences, 1998), El sentido del Derecho (2001), Bioética, Derecho y Argumentación (2004), El Derecho como Argumentación (2006), Para Una teoría postpositivista del Derecho (con Juan Ruiz Manero, 2009), Curso de Argumentación jurídica (2012).

Palabras clave: Argumentación jurídica, Filosofía del derecho, Enseñanza del derecho, Derecho $y$ Literatura, Abogados.

Abstract: Manuel Atienza (Oviedo, 1951) is the Head of the Department of Legal Philosophy, University of Alicante. Editor of DOXA - Cuadernos de Filosofía del Derecho and director of the Master in juridical argumentation. Former vice president of the World Association of Legal and Social Philosophy. He has been visiting professor at Harvard Law School and Cornell University. Doctor Honoris Causa by several Latin American Universities. Author of numerous articles and approximately 20 books, including: Las razones del derecho (1991), Tras la justicia (1993), Las piezas del derecho (together with Juan Ruiz Manero, 1996; (English version: A Theory of Legal Sentences, 1998), El sentido del derecho (2001), Bioética, Derecho y argumentación (2004), El derecho como argumentación (2006), Para una teoría postpositivista del Derecho (together with Juan Ruiz Manero, 2009), Curso de argumentación jurídica (2012).

Key words: Legal argumentation, Philosophy of law, Legal education, Law and Literature, Lawyers.

Juan Jesús Garza Onofre (JJGO): Javier Marías, relata que el filósofo rumano Michel Cioran no leía novelas, que al haber ocurrido tanto en el mundo, se preguntaba cómo podía inte-

\footnotetext{
${ }^{1}$ Llevada a cabo en Alicante, España, el 16 de julio de 2015. Agradezco al profesor Atienza, no solo por la presente entrevista, sino, y sobre todo, por su confianza y amabilidad. En igual sentido, quiero agradecer a los editores de Ciencia Jurídica y a Juan Luis Hernández Macías, por el apoyo para la realización de la presente entrevista.

${ }^{2}$ Investigador de la Facultad Libre de Derecho de Monterrey.
} 
resarse por cosas que ni siquiera habían acontecido; prefería las memorias, los diarios, la correspondencia... Las entrevistas.

Guardando sus debidas proporciones, una analogía parecida podría realizarse respecto a la falta de arraigo fáctico que muchas veces caracteriza a algún tipo de bibliografía jurídica. Sobre esa gran dosis de ficción en las teorías del derecho que evita comprometerse con la realidad y no solo termina por desatender el aspecto social, sino que también oculta y difumina las verdaderas intenciones de un determinado autor al momento de publicar. De ahí que muchas veces los prólogos y los epílogos, los intercambios epistolares, las entrevistas, puedan servir a manera de guía para desvelar algunas cosas que no siempre se encuentran explícitas en los textos académicos.

Dentro de tu amplia bibliografía, existe un importante número de entrevistas que has realizado a algunos de los teóricos del derecho más importantes de nuestra época. Desde los extintos, Norberto Bobbio, Felipe González Vicén, Aleksander Peczenik, Neil MacCormick, Renato Treves, hasta autores que al día de hoy ejercen una gran influencia en el campo jurídico. ¿Por qué entrevistar a un jurista? ¿Dónde radica su importancia?

Manuel Atienza (MA): Su importancia radica en lo que comentas. Yo he realizado muchas entrevistas; de hecho, desde el comienzo tenemos en la revista Doxa una sección dedicada exclusivamente a este género. Aparte de que, naturalmente, hay biografías que tienen un interés particular, se trata de dar contexto y de ayudar a entender las tesis teóricas de diversos autores.

Una entrevista es un género abierto en el que se pueden plantear cuestiones que no son propiamente de Derecho, y que sería impertinente que aparecieran en un trabajo académico. Pueden tener que ver con las aficiones literarias del entrevistado, con su manera de entender aspectos muy concretos de la política, con opiniones sobre la academia, y con cosas por el estilo. Creo que es un género muy interesante de cultivar.

Las entrevistas jurídicas son también, o deberían ser, una manera de abrir el mundo del Derecho hacia fuera, hacia otros mundos: hacia la política, hacia la literatura, hacia las ciencias sociales. Me parece que esa necesidad de apertura es una de las cuestiones pendientes más importantes. La cultura jurídica (sobre todo en nuestros países, en los países latinos) es muy cerrada, muy impermeable. Y en los dos sentido. Incluso diría que es más impermeable en la dirección de dentro hacia afuera, que de afuera hacia dentro. Es decir, hay muchos juristas (o iusfilósofos) que realmente están al día, que conocen lo que se realiza en filosofía, en ciencias sociales, etcétera; quizás menos de lo que se debiera, pero digamos que esa tendencia existe: muchos lo ven como una necesidad. Sin embargo, no me paree que pueda hablarse de una tendencia en la otra dirección. No hemos conseguido que filósofos, científicos sociales, ensayistas, literatos... muestren interés por el Derecho, quiero decir, por las cuestiones teóricas del Derecho. Ven el Derecho como algo que es importante desde un punto de vista práctico y a los juristas como gente poderosa, pero el Derecho no les interesa 
como empresa intelectual, y a los juristas nos miran, desde el punto de vista intelectual, un poco por encima del hombro.

Precisamente, acabo ahora de escribir un breve artículo sobre la filosofía del Derecho, en el sentido amplio de la expresión, de quien probablemente sea el escritor español más importante de las últimas décadas, Rafael Sánchez Ferlosio, que sí ha mostrado un genuino interés por el Derecho, aunque creo que él no comparte lo que podríamos llamar la "lógica funcional" del Derecho ${ }^{3}$. Mi estudio se limita a sus aforismos (a los que llama "pecios"), pero sería muy interesante extenderlo a otras de sus obras.

JJGO: ¿Si pudieras entrevistar a uno o varios personajes históricos, ya sea relacionados con el derecho, o no, quiénes serían y por qué?

MA: Entre los juristas, creo que me hubiera gustado mucho poder entrevistar a Rudolf von Jhering. Para mí representa alguien que verdaderamente captó el sentido del Derecho aunque, por supuesto, hoy uno no podría ser un seguidor estricto de Jhering. Pero creo que Jhering marcó la línea de la concepción del Derecho que a mí me interesa; más que, por ejemplo, Kelsen. Por otro lado, Jhering era un jurista abierto a muchos otros ámbitos de la cultura, como la música o la literatura.

Y, por supuesto, ¿a quién no le hubiera gustado entrevistar a pensadores como Platón, Aristóteles, Kant o Marx? Te cito estos nombres porque para mí son los grandes filósofos de la historia, los que creo que más me han influido.

JJGO: Por lo general, cuando tú has entrevistado a alguien, inicias preguntando sobre la trayectoria académica del autor, sobre sus orígenes y sus principales influencias: ¿Por qué decidiste trabajar en filosofía del Derecho? ¿Dónde estudiaste Derecho?, etcétera.

Aunque esta entrevista no pretende ser la excepción, en diferentes oportunidades que te han preguntado por tus inicios, incluso creo que tú mismo lo comentas en La guerra de las falacias, mencionas que lo que te interesaba era el periodismo (carrera que según tengo entendido estudiaste después) y la filosofía; pero que nunca te has arrepentido de estudiar derecho, y menos de involucrarte en la filosofía jurídica, sobre todo por esa combinación de lo que es la importancia práctica del derecho y el análisis teórico.

Ahora bien, recientemente, en una conversación que tuvimos, declaraste que en tu juventud contemplaste también la idea de dedicarte a las letras. De ser escritor. De escribir literatura. Y es que tanto literatos como juristas tienen el común denominador de ser personas que profesan y cultivan las letras ¿Nos podrías hablar sobre eso?

MA: Bueno, yo creo que probablemente lo que a mí más me ha marcado de todo lo que he leído en mi vida son los Diálogos de Platón, que leí siendo adolescente. Los Diálogos son una obra que puede leer, prácticamente, cualquier persona; aunque, naturalmente, las interpre-

3 Manuel Atienza, ““Peripecios”. Sobre la filosofía del derecho de Rafael Sánchez Ferlosio”, en La mirada de Pheito: http://lamiradadepeitho.blogspot.com.es, 20 de julio de 2015. 
taciones van a ser distintas según la edad, experiencias, formación, etc. Pero yo encontré ahí, unidos, lo que eran mis dos principales centros de interés: la literatura y la filosofía.

En el sistema educativo español, de entonces y de ahora, uno tiene que tomar la decisión sobre qué estudiar en la universidad cuando todavía se es muy joven, y la verdad es que resulta muy difícil tomar la decisión con suficientes fundamentos. A mí, por ejemplo, me gustaba mucho no sólo la filosofía sino también el griego; y quizás no estudié griego en la universidad porque el profesor que tenía en el colegio de secundaria al que iba, y que era excelente, se fue a la mitad del curso y fue sustituido por otro que no lo era. También es verdad que nuestras mentes, nuestros cerebros, son sumamente dúctiles, de manera que hay muchas cosas para las que uno podría estar capacitado cuando inicia sus estudios en la universidad y que pueden terminar por convertirse en una vocación; también, claro, hay cosas para las que uno no vale. En fin, yo creo que la intuición que tuve al decidir estudiar Derecho fue acertada. Siempre me interesó la filosofía, pero mi motivación para ello era más que satisfacer una curiosidad intelectual, procurar de alguna forma cambiar las cosas. De manera que la filosofía del Derecho, que forma parte de la filosofía práctica, era una buena opción. Y como estudiante, siempre tuve claro que me interesaba más la filosofía del Derecho que propiamente el Derecho.

El Derecho, tal y como se enseñaba y, me parece, se sigue enseñando en nuestras universidades, es algo verdaderamente muy aburrido; con muy pocos alicientes desde el punto de vista intelectual. Además, los profesores que yo tuve en Oviedo de las materias de Derecho natural (como entonces se llamaba) en el primer curso de la carrera y de filosofía del Derecho, en el último, en quinto, no es que no fueran buenos, sino que eran muy malos. De manera que mi mayor interés por la filosofía del Derecho, en relación con las otras materias que estudiábamos, no se debió a lo que aquella universidad ofrecía. Se debía a otras motivaciones. Aunque, de todas formas, al poco de terminar yo la carrera ganó la cátedra de filosofía del Derecho en Oviedo Elías Díaz, y entonces las cosas cambiaron drásticamente. Con él hice mi tesis de doctorado y él fue quien guió mis pasos durante los primeros años. Si no hubiese tenido ese golpe de suerte, creo que tampoco me hubiese arrepentido de la opción que tomé. Cada vez me parece más claro que el Derecho no solamente es algo importante desde el punto de vista práctico, una institución de la que depende la vida de la gente, sino que además tiene un gran interés teórico. Yo creo que hay pocas empresas racionales (para emplear la expresión de Toulmin) en donde la articulación entre la teoría y la practica estén más presentes que en el Derecho. Pero lamentablemente, los propios juristas no suelen ser conscientes de ello, de que necesitan a la filosofía del Derecho para poder ser buenos juristas. Alguna vez he dicho, con intención provocadora, que lo que habría que estudiar en las Facultades de Derecho de manera central sería filosofía del Derecho y que al resto de las materias habría que considerarlas como complementarias.

JJGO: La relación entre el derecho y la literatura es manifiesta. Es bien conocido que un gran número de personas que han comenzado estudiando derecho, terminan escribiendo literatura, o bien sencillamente abandonando la primer carrera, o por el contrario, utilizan- 
do el derecho como trampolín para ejercer el oficio de la escritura, o incluso adecuándolo y haciéndolo compatible con otras actividades afines.

De hecho, dentro de los 111 premios Nobel de literatura que se han entregado, en 107 ocasiones desde 1901 hasta 2014, 17 laureados han tenido alguna relación con el derecho. Se podría decir que Theodor Mommsen, quien era romanista y catedrático de derecho en distintas universidades en Europa, fue el único que realmente ejerció la profesión jurídica, pues del total de los galardonados, 6 de ellos (entre los que destacan Octavio Paz, Jacinto Benavente o Juan Ramón Jiménez) abandonaron la carrera y los demás, sencillamente, nunca ejercieron o más bien prefirieron dedicarse por entero a la creación literaria (Vargas Llosa, García Márquez, Miguel Ángel Asturias, Camilo José Cela, por mencionar solo algunos).

¿Nunca es tarde para abandonar el derecho?, o más bien dicho ¿Siempre es buen momento para dedicarse por entero a la creación literaria?, o ¿prefieres la idea de tender puentes entre el derecho y la literatura? ¿Qué crees que es más difícil escribir una novela o una obra jurídica?

MA: Lo difícil es escribir algo que sea realmente bueno: bien se trate de una novela o de un libro jurídico. Es posible que la explicación para esos datos de que hablas, al menos en el caso español y del mundo latino en general, sea que el Derecho ha sido hasta hace poco una especie de Studium Generale al menos para las ciencias sociales.

Las personas que aspiraban a ser literatos y querían tener algún tipo de formación universitaria estudiaban Derecho, no porque tuvieran vocación de ser juristas, sino porque eso les abría muchas posibilidades. También por cuestiones familiares. Probablemente, en algunos de esos casos a los que te has referido se trataba de una especie de transacción, es decir, ellos querían dedicarse a la literatura pero sus padres les presionaban para que estudiaran antes la carrera de Derecho, como una especie de seguro de vida.

Por cierto, he estado leyendo recientemente un libro sobre Ortega y Gasset, y al parecer él también había estudiado Derecho. No lo sabía. Pero es que en España, hasta hace poco, una buena proporción de quienes han tenido una proyección pública han estudiado Derecho. Si bien, como te decía antes, una cosa es el Derecho y otra cosa el estudio del Derecho en las Facultades que, en general, resulta poco interesante y poco estimulante. Yo creo que eso explica en parte el rechazo que sienten por el mundo del Derecho los intelectuales y que antes comentábamos. En general, la idea que se tiene del Derecho es sumamente pobre y formalista: se piensa que el Derecho es un archivo de datos, de normas jurídicas y que resolver problemas jurídicos consiste simplemente en encontrar la norma pertinente. No se piensa en la importancia que tienen los procesos de interpretación y de argumentación, la necesidad de poseer imaginación jurídica, etc. Por otro lado, el Derecho, como en general las cuestiones que conciernen a la razón práctica, requieren una gran madurez. Eso es algo de lo que era muy consciente Aristóteles cuando señalaba (creo que era en la Retórica) que un joven puede ser matemático, geómetra, pero no puede ser un político (en el sentido amplio de la expresión), porque la prudencia sólo puede adquirirse con mucha experiencia. 
JJGO: Me recordaste aquella frase que dice: "Los estudiantes entran creyendo en la justicia y salen creyendo en el derecho".

MA: Sí, me parece que es bastante cierto. Es relativamente frecuente encontrarse con estudiantes que en el primer curso son personas abiertas, con ideales, etc. y que van perdiendo esas cualidades a medida que van progresando en la carrera. Todo un proceso de socialización.

JJGO: Algo de lo que más me llamó la atención de tu Curso de Argumentación jurídica ${ }^{4}$ es el capítulo X. El capítulo menos jurídico de todo el libro, pero creo que el más sincero, sensato y sobre todo literario. ¿Cómo gestaste este capítulo? ¿Existe la posibilidad de seguir desarrollando dicho estilo en tus futuros trabajos? ¿Has pensado en escribir una "novela jurídica"?

MA: No, una novela jurídica no. A mi (como a tanta gente), naturalmente me gustaría ser capaz de escribir una buena novela, un buen cuento...lo que sea. Pero es muy difícil. Y uno tiene que ser capaz de saber lo que puede y lo que no puede hacer.

Lo que sí me viene interesando desde hace mucho tiempo es el Derecho y la literatura. Aquí, en el departamento de filosofía del Derecho de la Universidad de Alicante, hicimos unos cuantos seminarios sobre eso. $\mathrm{Y}$ yo he escrito algunas cosas relacionadas con ese tema, pero que no he publicado. Uno de estos escritos es sobre el Quijote y el Derecho: un tema de enorme interés. Mi tesis es que la clave para entender los diversos pasajes del Quijote que hacen referencia al Derecho es el concepto de compasión, de piedad, o como se lo quiera llamar: aparece en el episodio de Andresillo, de los galeotes, de la justicia impartida por Sancho Panza...Hay algunos estudios sobre eso, pero el movimiento Derecho y Literatura procede de los Estados Unidos y, por ello, está muy centrado en la literatura anglosajona. Pero en la literatura en español hay una extraordinaria riqueza que yo creo está todavía poco explotada.

También escribí algo sobre un relato de Azorín: El buen juez. Azorín es un escritor de aquí, de un pueblo de Alicante, y es bastante curioso. Un conservador, en el sentido más profundo de la expresión pero, al mismo tiempo, yo creo que un gran escritor. Y tiene un cuento que está inspirado en el famoso juez Magnaud, al que se llamó "el buen juez", de finales del XIX y comienzos del XX que, de alguna manera, viene a ser el antecedente de los jueces estrella de nuestros días. Está vinculado con la revuelta contra el formalismo jurídico.

Creo que todo esto es un enfoque de gran importancia que hay que desarrollar. Otorga perspectiva a los juristas, contribuye a desarrollar su imaginación y les proporciona incluso instrumentos metodológicos de interés. Sabemos que el Derecho no es como la literatura

\footnotetext{
4 Manuel Atienza, Curso de argumentación jurídica, Trotta, Madrid, 2013. 
(recordemos el título del famoso artículo de Dworkin), no es lo mismo interpretar el Derecho que un texto literario, pero hay algunas afinidades interesantes.

Hace poco hablaba con un abogado gallego que había escrito varios textos literarios, y me comentaba que, cuando él se ponía a escribir, dejaba completamente de lado al Derecho y trataba de hacer algo completamente distinto: literatura de vanguardia o algo por el estilo. Yo le sugería que quizás no hiciera tan bien y que era una pena que no aprovechara el increíble material literario con que puede encontrarse un abogado. No sé si has leído los relatos de un abogado alemán, Ferdinand von Schirach. A mí me parecen magníficos. ${ }^{5}$ Un ejemplo estupendo de cómo combinar el Derecho y la literatura, de cómo aprovechar el material jurídico para hacer buena literatura.

JJGO: Alguna vez destacaste Normative Systems de Carlos Alchourrón y Eugenio Bulygin, y El Concepto de Derecho de Hart como dos obras cruciales dentro de tu formación, y de la filosofía del derecho en general. ¿Podrías realizar el mismo ejercicio pero en literatura?

MA: Las dos obras literarias que a mí más me gustan son dos clásicos: el Quijote y Las mil y una noches.

JJGO: Para Borges un clásico es "aquel libro que una nación o un grupo de naciones o el largo tiempo han decidido leer como si en sus páginas todo fuera deliberado, fatal, profundo como el cosmos y capaz de interpretaciones sin término". Sin embargo, Mark Twain escribió que un clásico es "un libro que la gente elogia pero no lee”. ¿Qué opinas? ¿Por qué habría que leer a los clásicos?

MA: Mark Twain tenía probablemente razón. Hace poco leía unas estadísticas sobre el número de españoles que decían haber leído el Quijote, y que parecía no coincidir mucho con el número de los que realmente lo han leído. Pero una persona que se considera culta en España parece que se siente obligada también a haber leído el Quijote, y eso puede ser la explicación de ese desajuste estadístico. Aunque quizás esto sea ya cosa de otro tiempo, de otra generación. Yo creo, por ejemplo, que a mis estudiantes les trae más bien sin cuidado el haber leído o dejado de leer el Quijote o lo que sea.

En todo caso, ¿por qué habría que leer a los clásicos? Yo creo que porque en los clásicos está de alguna forma todo, o casi todo, aunque, por otro lado, pueda haber elementos azarosos que hayan hecho que determinadas obras se conviertan en clásicas. Probablemente se hayan escrito obras que en abstracto sean tan valiosas como las que consideramos obras clásicas y a las que, sin embargo, no les damos ese trato. Pero lo que pasa es que en relación con los clásicos ya no importa únicamente, por así decirlo, el texto original, sino también todas las interpretaciones, todas las influencias que el texto fue dejando en los que pasaron por él. Sería una explicación para lo que Borges decía.

A mí me ocurre con la literatura que me gusta muchísimo, pero no tengo mucho tiempo para leer. Por eso, tengo que hacer una selección muy estricta. A lo mejor es equivocado,

${ }^{5}$ Vid. Ferdinand Von Schirach, Crímenes, traducción de Juan de Sola, Salamandra, Barcelona, 2011; vid. Ferdinand Von Schirach, Culpa, traducción de María José Díez Pérez, Salamandra, Barcelona, 2012. 
pero el criterio que he seguido se centra en los autores clásicos, en los valores seguros. Hay veces que no queda otra que ser conservador.

JJGO: ¿Quiénes serían los clásicos dentro de la filosofía del derecho?

MA: Bueno, los clásicos en el siglo XX obviamente han sido Kelsen, Hart, Ross, aunque este último tiende a no ser considerado tan importante, pero sí que lo es, su libro Sobre el Derecho y la justicia es uno de los grandes libros del siglo pasado. Y luego Bobbio, un autor que no es tan conocido fuera del mundo latino, pero cuya importancia es enorme.

Todos ellos son positivistas jurídicos, pero me parece que ninguno de ellos está en la línea de Jhering; quizás el que más se le acerque sea Ross. Pero, claro, los anteriores son los clásicos desde el punto de vista de un filósofo del Derecho europeo. Si nos situáramos en una perspectiva estadounidense, habría que incorporar por lo menos a Holmes, y la conexión de este último con Jhering sí que es estrechísima.

Y por lo que se refiere a los contemporáneos, los nombres que yo dará serían los de Dworkin, Nino, Alexy y MacCormick.

JJGO: Según William Twining, ${ }^{6}$ al hacer referencia a la teoría del derecho que se enseña actualmente dentro de la tradición anglo-americana, es posible percibir una corriente dominante de pensamiento ubicada en autores como Dworkin, Hart, Kelsen, el Derecho Natural, Rawls y Raz; y después, aunque ya en un segundo nivel, en juristas como Austin, Bentham, Fuller, Holmes, Llewellyn, MacCormick, Pound, los Critical Legal Studies y quienes conforman la teoría jurídica feminista.

Esta idea, a mi parecer, provoca diferentes reflexiones que bien vale la pena ir desgranando una por una.

La primera. ¿Dónde está Jhering dentro de la teoría jurídica que se enseña hoy en día?, resulta bastante significativo el hecho de que hasta hace solo un par de años, y después de más de un siglo de la muerte de este jurista alemán, se publicara la primera obra monográfica en Hispanoamérica respecto a su pensamiento. ¿Por qué intuyes que este autor no ha sido tomado en cuenta? ¿Cómo podría reivindicarse la teoría de este autor hoy en día?

MA: Quizás habría que matizar que la influencia de Kelsen, a pesar de que este viviera una buena parte de su vida en los Estados Unidos, ha sido relativamente escasa allí, porque su concepción del Derecho, yo creo, no encajaba con la cultura jurídica estadounidense. Y por lo que se refiere a Jhering, yo creo que su influencia está muy presente a través del realismo jurídico. Lo que pasa es que en ese mundo hay una cierta tendencia a olvidar la historia, o a conocer solamente una historia. Y ello puede explicar que no se sea consciente de lo que significó Jhering. Pero, por ejemplo, cuando uno lee las famosas frases de Holmes

\footnotetext{
${ }^{6}$ William Twining, "Implicaciones de la globalización para el derecho como disciplina”. Anales de la Cátedra Francisco Suárez, Departamento de Filosofía del derecho de la Universidad de Granada, Vol. 44, 2010, pp. 349 y 350.
} 
sobre el papel de la lógica en el Derecho, se da cuenta de que son casi trascripciones literales de fragmentos de Jhering.

Sin duda, Jhering fue el gran jurista del siglo XIX, o al menos de la segunda mitad del siglo. Yo creo que esto fue algo indubitable para la cultura jurídica de una cierta época, incluida la del mundo latino. Y lo que ocurrió es que luego esa idea se perdió, y la influencia de Jhering fue sustituida por la de Kelsen, que jugó un papel hegemónico (en competencia a veces con las tradiciones iusnaturalistas) en los países del mundo latino. Piensa, por ejemplo, en lo que ocurrió en Argentina: el país más kelseniano del mundo, yo diría. Claro, si uno compara a Kelsen con nuestros iusnaturalistas, la diferencia es simplemente abismal y eso explica que todos los que significaron algo en los años de las décadas centrales del siglo XX fueran de alguna forma kelsenianos. Pero, te insisto, yo veo el sentido de lo que es (o debería ser) el Derecho más en la obra de Jhering que en la de Kelsen. Y si el papel que jugó Kelsen lo hubiera desempeñado Jhering, es posible que también nosotros hubiésemos tenido corrientes de realismo jurídico. En fin, tampoco se trata de mitificar a Jhering. Y su obra está construida en un contexto que es muy distinto al actual. Él fue, por ejemplo, un romanista, y recuerdo que en alguna ocasión escribió que si pudiera dar marcha atrás en el tiempo no se hubiese ya ocupado profesionalmente del Derecho romano. Como pasa también con muchos de los autores clásicos, merece la pena leerlos como fuentes de inspiración, pero uno no podría decir hoy que para manejarnos en nuestros sistemas jurídicos lo que habría que hacer es estudiar básicamente a Jhering. No, esto no es así. El fin en el Derecho es una obra que hoy es difícil de leer; tiene una sistemática compleja, está escrita en un estilo que es muy distinto al de Kelsen y los otros autores mencionados. En alguna ocasión he escrito que alguien tendría que hacer con Jhering una labor de recopilación de sus aforismos; porque él fue además un gran escritor.

JJGO: La segunda, respecto a la ausencia de mujeres dentro la filosofía jurídica.

Parecería que el transcurso de la historia que formula la impostergable emancipación femenina, ha provocado que de un tiempo para acá, lo dice Lipovetsky, "ninguna especialidad puede ya considerarse feudo exclusivo del sexo masculino"?

Sin embargo, a pesar de la incorporación del género femenino en el campo jurídico de manera más o menos regular, y del incremento en los últimos años respecto al número de mujeres que ejercen como abogadas, en la filosofía del derecho las mujeres al final del día, quedan mal representadas pues no solo es que sean más bien pocas quienes ocupan cargos decisivos o influyentes en el ámbito académico, sino que sencillamente no existe una visión que incorpore los temas de género y feminismo, propiamente, a la filosofía del derecho. ¿Qué opinión te merece dicha reflexión?

MA: La situación es parecida a la que se da en la filosofía o en las diferentes ciencias sociales. Hay algunos nombres importantes de mujeres, pero muy pocos, y todos de los últimos años o décadas. La explicación es, por lo demás, obvia. Recuerdo que la primera mujer juez que hubo en España fue después de que yo empezara a estudiar Derecho. De todas formas,

7 Gilles Lipovetsky, La tercera mujer, Anagrama, Barcelona, 1999, p. 226. 
las cosas parecen haber cambiado bastante en los últimos tiempos. Tanto en España como en muchos otros países, cada año se incorporan a la judicatura más mujeres que hombre. El fenómeno no es todavía muy perceptible, porque aún han llegado pocas a la cúspide judicial. Pero obviamente es cuestión de tiempo. Y lo mismo ocurrirá, claro, con la filosofía del Derecho.

JJGO: La tercera y última, respecto a lo aducido por Twining, sobre la enseñanza del derecho y el carácter regional de la filosofía del derecho. ¿Qué es lo que se enseña en las facultades? ¿Qué tipo de filosofía del derecho se transmite dentro de las Universidades? Y más en Norteamérica. Precisamente cuando entrevistaste a Riccardo Guastini ha dicho que "Los anglosajones no conocen otra lengua que la propia, así que no saben nada de lo que se publica en Europa continental o en América latina, y sus trabajos son completamente autoreferenciales". ¿Es posible que los estadounidenses menosprecien o infravaloren la teoría jurídica del mundo latino? Eso por un lado, pero por otro, ¿no te parece que a veces como latinos se peca de un cierto fetichismo por adular todo aquello que venga de la tradición anglosajona? Tú mismo has realizado dicha reflexión al momento de rescatar la figura de Vaz Ferreria.

MA: Sí, creo que Guastini tiene toda la razón. Habría alguna excepción que hacer, pero por lo general es así. Ignoran absolutamente todo lo que no sea su propia tradición. Pero yo no creo que sea soberbia intelectual o cosa semejante. Simplemente, no les interesa.

Yo he hecho algunas estancias de investigación en los Estados Unidos. No puedo decir que tenga un conocimiento profundo de sus universidades, pero tengo cierta información directa de cómo funcionan sus Facultades, o escuelas, de Derecho. En ellas hay una concepción del Derecho muy localista. No les interesa, por ejemplo, mucho el Derecho internacional. El mundo del Derecho para ellos es el Derecho de los Estados Unidos. Y, por cierto, creo que esto no ocurre sólo con el Derecho. Si vas, por ejemplo a la prensa, la información internacional prácticamente no existe, salvo en dos o tres periódicos. Pero como te decía, no creo que se les pueda reprochar mucho. $\mathrm{O}$, mejor dicho, su responsabilidad es más bien a título de culpa que de dolo. Pueden actuar así, porque el país tiene un tamaño y un poder que no les supone aislamiento. Lo peor es lo que ocurre en nuestros países: que aceptamos esa situación de colonialismo cultural, sin darnos cuenta de lo que supone. Pues para que se dé un fenómeno de dominación (cultural o no) es necesario que los que obedecen hayan interiorizado en buena medida esa situación; no se sienten obligados a hacerlo: quieren hacerlo. Y lo que tenemos es una situación bastante absurda. Digamos que, en relación con los autores de primera línea, un Dworkin por ejemplo, es lógico que les prestemos atención: que uno los estudie y trate de asimilar lo que ellos aportan. Pero el problema es que tenemos también una especie de actitud reverencial hacia los de segunda y tercera fila. Los preferimos a los nuestros, incluso cuando estos últimos son autores de gran nivel e intelectualmente superiores a los otros. Es una situación que deberíamos corregir aunque, al mismo tiempo, es preciso ir con cuidado. No se trata de cerrarse culturalmente, de volverse localistas. Pero

\footnotetext{
${ }^{8}$ Manuel Atienza, "Entrevista a Riccardo Guastini”, en Doxa: Cuadernos de Filosofía del Derecho, No. 27, 2004 , p. 461.
} 
entre el colonialismo y el localismo, el provincianismo, hay un terreno que es el que deberíamos tratar de ocupar.

Hay aquí un punto que es crucial. Una obviedad, yo creo, pero que la gente no parece estar muy dispuesta a ver. Se trata de que la filosofía del Derecho, en cuanto disciplina, no funciona como funcionan las matemáticas, la física o la biología. Estas últimas son, digamos, disciplinas genuinamente universales. Si alguien descubre algo verdaderamente importante en esos ámbitos, puede estar seguro de que se le va a reconocer, de que se va a incorporar al acervo común. Pero en la filosofía del Derecho, o en la filosofía, las cosas no son así. Son disciplinas muy vinculadas a un medio cultural. No existe, para decirlo claramente, un foro de discusión mundial en el que se practique lo que suele llamarse un discurso racional, en el que todos los participantes estén en igualdad de condiciones. Y lo que ocurre es que, en ese contexto dominado por la cultura anglo-americana, muchas veces da la impresión de que la aspiración de los autores latinos es simplemente la de poder llegar a ser citados por alguno de esos autores anglos...digamos, en nota a pié de página. Y yo creo que deberíamos reaccionar frente a esa situación: podemos, y debemos, aspirar a más.

JJGO: En este mismo orden de ideas, para el próximo año, y bajo la dirección de la escuela alicantina, se está gestando el "Primer Congreso de Filosofía del Derecho del Mundo Latino", ¿' ¿nos puedes hablar un poco del mismo y de sus objetivos?

MA: Los objetivos son estos que acabo de comentarte. Los países latinos, de Europa y de América, no son del todo homogéneos, pero no obstante esto, fácilmente uno se da cuenta de que pertenecemos al mismo ámbito cultural y de que compartimos muchas cosas; entre otras, tener una tradición muy rica en estas cuestiones.

Y el ejemplo de Vaz Ferreira, al que te referías antes, es muy significativo de esa situación. Pocos filósofos del Derecho de nuestros países (o de otros) han oído alguna vez ese nombre. Y, sin embargo, él es, por así decirlo, el precursor de los precursores de las teorías de la argumentación jurídica. Y hay más autores importantes a los que deberíamos también recuperar. Tenemos una tradición de la que no somos muy conscientes. Por otro lado, como te decía, no se trata tampoco de ignorar la filosofía del Derecho anglo-americana. Es obvio que hay muchos temas y muchas cuestiones metodológicas comunes. Pero tenemos que ser capaces también de poner en el centro las cuestiones que a nosotros más deberían importarnos: por ejemplo, los derechos sociales o el problema de la anomia. Bueno, estos son algunos de los temas propuestos para este próximo congreso en Alicante. En el que trataremos también de establecer un método de discusión que pueda resultar más fructífero de lo que suele ocurrir en los congresos, introduciendo la figura de un relator, encargado de organizar el material que haya llegado en relación a cada uno de los temas, para centrar los puntos de la discusión. Hay que aprovechar la circunstancia de que hoy existe un buen número de iusfilósofos con un alto nivel de cualificación y el hecho de que fuera de la propia filosofía del Derecho existe

\footnotetext{
9 Para mayor información: http://iusfilosofiamundolatino.ua.es
} 
también un interés por las cuestiones teóricas, la consciencia de que la (buena) práctica depende de la (buena) teoría.

JJGO: Ahora bien, y siguiendo con lo del carácter regional de la filosofía del derecho, ¿crees que se podría hablar de derecho en culturas no occidentales? ¿Qué papel desempeña la argumentación en otras culturas jurídicas, si es que te lo has planteado? ¿Las teorías de la argumentación se hacen cargo de la diversidad de culturas jurídicas en el mundo?

MA: El Derecho no es un fenómeno natural, sino una creación social, cultural, y por eso ha habido y hay grandes diferencias entre los diversos sistemas jurídicos. Pero el Derecho (algún tipo de organización jurídica de la sociedad) parece ser también una necesidad, algo objetivo, cuando las sociedades adquieren cierto grado de desarrollo (y cierto nivel de conflicto). Por otro lado, como las tradiciones han sido distintas (pensemos en nuestros Derechos de tipo continental frente al common law), también lo son las instituciones y a veces los estilos argumentativos, el mayor uso de unas u otras técnicas argumentativas, etc. Pero hay también lo que podría llamarse una especie de equivalencia funcional: las sociedades que son parecidas desde el punto de su organización económica, su desarrollo tecnológico, etc. tienden también a tener sistemas jurídicos semejantes (funcionalmente semejantes). Eso explica que el giro argumentativo del que solemos hablar no sea privativo de una sola cultura (por ejemplo, la del mundo latino) y que el tipo de teoría y de técnicas argumentativas que necesita manejar un jurista sea muy semejante si, por ejemplo, estamos hablando de sistemas jurídicos del Estado constitucional.

JJGO: ¿A qué crees que se deba el descuido por parte de la teoría estándar de la argumentación jurídica respecto a los abogados?

MA: Pues probablemente a que no hay teóricos del Derecho, o no hay muchos que yo sepa ahora, que sean abogados. Seguramente porque el ejercicio de la profesión es tan absorbente que quizás no deje tiempo para hacer otra cosa. En ese sentido es distinta de la judicatura. Un juez no es un abogado al que le vence el plazo para presentar un recurso, como es un funcionario, normalmente se jubila a una edad que le deja aún tiempo para una actividad intelectual, etc. Aunque quizás todo esto esté cambiando: en España, por ejemplo, no es infrecuente que un juez que ha dejado de pertenecer a un tribunal (por haberse jubilado o no) pase a trabajar de abogado lo que, por cierto, no me parece lo más recomendable desde el punto de vista ético.

JJGO: Robert Alexy afirma que la argumentación jurídica es un caso especial del discurso racional. ¿La de los abogados es un caso especial de discurso racional? ¿El abogado que argumenta bien, es el que sigue sus reglas?

MA: No, yo creo que eso es un error manifiesto de la teoría de Alexy. Esa crítica se le hizo prácticamente desde el momento en que apareció su libro de 1978, pero él no considera que sea tal. En mi opinión, es una de las muestras más claras de que su concepción de la argumentación presupone una visión bastante idealizada del Derecho.

Yo creo que para construir una teoría de la argumentación que de cuenta de todo lo que son nuestras prácticas argumentativas no podemos quedarnos solo con la teoría del dis- 
curso. Existen muchos contextos en los que se argumenta en el Derecho y en donde no se siguen las reglas sistematizadas por Alexy. Ese alejamiento es particularmente importante en el caso de la argumentación de los abogados, y es menos notorio si uno se centra en la argumentación de la dogmática o de los tribunales (sobre todo en las altas cortes).

Pero, dicho esto, creo que también es importante añadir que el hecho de que la argumentación de los abogados no pueda verse como un caso especial del discurso racional no implica ningún desdoro para la profesión. $\mathrm{O}$ sea, no significa que nos encontremos frente a una profesión sucia, o algo por el estilo. Simplemente, la abogacía es una institución diferente a la judicatura y, por eso, tiene ciertas especificidades argumentativas. Pero, por lo demás, el que no constituya un caso especial de la argumentación práctica racional no quiere decir que no tenga ningún contacto con ese discurso. Lo tiene porque, aunque pueda parecer una paradoja, el discurso racional permite justificar que exista un discurso (el de los abogados) que no cumpla completamente con esas reglas y autorice, por ejemplo, a no ser sincero, si bien con ciertos límites.

JJGO: Tu visión de la abogacía es que esta no es una profesión intrínsecamente inmoral, pero sí una profesión de riesgo moral. ¿Se te ocurren algunas herramientas o procesos para lograr dicha concepción?

MA: Los códigos deontológicos sin lugar a dudas pueden jugar un papel, pero quizás no sea el único instrumento. En una de las últimas cosas que he escrito sobre esto, aparece una propuesta (de un autor estadounidense) que me parece interesante: se trata de recurrir al diálogo como herramienta para abordar problemas éticos de la abogacía. El diálogo con el cliente que pretende llevar a cabo una actuación que plantea problemas éticos al abogado, o el diálogo entre los propios profesionales, los miembros de un despacho jurídico. Como digo, puede ser un buen instrumento para identificar dónde hay un problema ético y dónde hay que poner una línea roja, un límite que el abogado no debería traspasar por razones morales.

JJGO: ¿Deben los abogados saber filosofía?

MA: Por supuesto. Pero no se trata simplemente de que deban saber filosofía por cuestiones, digamos, ornamentales, para ser un abogado culto, etc. Se trata de que, en mi opinión, no se puede ser un buen abogado si no se tiene cierta formación en filosofía y en teoría del Derecho. Por ejemplo, si lo que hace el abogado es, fundamentalmente, argumentar, parece bastante razonable pensar que quien sabe algo de teoría de la argumentación (lógica, teoría de la interpretación, etc.) va a estar en mejores condiciones para desempeñar su profesión. Un ejemplo bien importante es el de Genaro Carrió, a quien considero uno de mis maestros: el fue un gran abogado y un gran teórico del Derecho, y la teoría del Derecho sin duda con- 
tribuyó a que fuese tan buen abogado. Se puede ver esa influencia en un estupendo librito que escribió dando consejos a los abogados noveles.

JJGO: ¿Vaz Ferreira también ejerció como abogado, no es así?

MA: Sí, pero Vaz Ferreira muy poco. Y Vaz Ferreira siempre tuvo la preocupación de que la abogacía fuese una profesión intrínsecamente inmoral. Sobre esto escribió algunas páginas de gran interés, quizás un tanto ambiguas.

JJGO: Si bien son conocidos los principales aportes que has hecho en el campo de la filosofía del Derecho, en este caso te preguntaría lo contrario, ¿qué crees que falta por desarrollar dentro de tu obra?

MA: Pues ahora estoy trabajando en un libro cuyo título será "Filosofía del Derecho y transformación social". Es como un complemento de una teoría argumentativa del Derecho. Se trata de ver el Derecho desde una perspectiva más amplia y de poner el énfasis en la transformación social, que tendría que ser el objetivo final, yo creo, de cualquier buena teoría del Derecho.

JJGO: Jhering, Radbruch, Wittgenstein... Grandes pensadores han cambiado sustancialmente sus propias opiniones. ¿Consideras que es posible hablar de un giro dentro de tu trayectoria? ¿Cómo ha sido tu evolución en cuanto filósofo del derecho? ¿Se puede hablar de etapas en tu producción iusfilosófica? ¿Cuáles serían?

MA: Cambios, por supuesto, sí. Pero yo diría que la idea que tengo hoy de la filosofía del Derecho, en lo esencial, no es muy diferente de la que siempre he tenido. O sea, los objetivos son los mismos pero, claro, hay muchas cosas que hoy veo de manera muy distinta a como las veía antes. Si quieres, de las dos grandes motivaciones que pueden llevarle a uno a dedicarse a la filosofía del Derecho, y de las que hablábamos antes, la curiosidad intelectual, y el propósito de cambiar las cosas, la segunda ha sido para mí más importante. Recordando la famosa tesis de Marx sobre Feuerbach: "los filósofos se han limitado a interpretar el mundo de distintos modos; de lo que se trata es de transformarlo". Yo pienso que las dos cosas (como lo pensaba Marx) tienen que ir unidas: pretender transformar sin haber entendido es un disparate. Pero me parece que he sido (que soy) un filósofo del Derecho más práctico que curioso. El afán de originalidad que muchos parecen tener como meta fundamental de su trabajo a mí me deja bastante frío. Para mí lo importante es que la teoría sirva para algo, para algo que merezca la pena y que no sea simplemente presentar de alguna manera muy original o llamativa lo que ya es muy sabido. Recuerdo que Gustavo Bueno solía hablar de implantación gnóstica y de implantación política de la filosofía, con lo que quería decir lo mismo que vengo comentando: la curiosidad y el afán de transformación. Necesitamos ambas cosas, insisto, pero el papel directivo tiene que tenerlo el segundo elemento. Nuestra implantación de la filosofía del Derecho tendría que ser política.

A veces, alguien me ha dicho: "pero tú eras un iuspositivista y ahora has dejado de serlo". Bueno, te confesaré que a veces he tenido dudas al respecto y me he puesto a revisar cosas que había escrito hace tiempo. Y el resultado es que nunca, que yo sepa, me declaré 
iuspositivista, aunque es verdad que ahora pongo mucho énfasis, lo que no hacía antes, en la necesidad de superación del positivismo jurídico. Creo que la explicación es que en los primeros años de mi formación, al final del franquismo, la filosofía analítica y la marxista (la dialéctica) no se veían como algo necesariamente antagónico. Si hubiera sido un iusfilósofo estrictamente analítico, como los argentinos, con seguridad que me hubiese declarado iuspositivista. Pero lo que evitó eso, yo creo, fue la influencia marxista. Y hoy sigo creyendo, por cierto, que una buena filosofía del Derecho no tendría que abandonar el método analítico (otras cosas de la iusfilosofía analítica, sí), ni tampoco la tradición de pensamiento de la que Marx es un hito fundamental. 